\title{
FORMULATION AND EVALUATION OF GASTRORETENTIVE FLOATING BIOADHESIVE TABLETS OF HYDROCHLOROTHIAZIDE
}

\author{
RAMU B*, SHANMUNGA PANDIYAN P
}

Department of Pharmacy, Mewar University, Chittorgarh, Rajasthan, India. Email: Bandameedi.ramu@gmail.com

Received: 17 January 2016, Revised and Accepted: 13 February 2017

\begin{abstract}
Objective: Floating bioadhesive tablets of hydrochlorothiazide were developed to prolong gastric residence time leading to an increase in drug bioavailability where here a combination of floating and bioadhesion mechanism is combined.
\end{abstract}

Methods: Tablets are prepared by direct compression technique using polymers xanthan gum, carbopol 974 P, HPMC K15M, HPMC K100M, magnesium Stearate USP-NF (Avicel PH 102), microcrystalline cellulose Ph 102, Talc, and sodium bicarbonate.

Results: Tablets were evaluated for their physical characteristics, namely, hardness, thickness, friability and weight variation, drug content, and floating properties. The best formulation subjected for kinetic treatment, i.e., zero order, first order, peppas, Higuchi, and Hixon-crowel. The R values are $0.9366,0.9364,0.9680,0.9974$, and 0.9283 , respectively.

Conclusion: Optimized formulae F4 containing polymers HPMC K4M and CARBOPOL 974 P showed more bioadhesion with a controlled release over $12 \mathrm{hrs}$. Therefore, formulation F4 identified as a successful formulation for the development of floating bioadhesive tablets.

Keywords: Hydrochlorothiazide, Floating tablets, Gastroretentive drug delivery system.

(C) 2017 The Authors. Published by Innovare Academic Sciences Pvt Ltd. This is an open access article under the CC BY license (http://creativecommons. org/licenses/by/4. 0/) DOI: http://dx.doi.org/10.22159/ajpcr.2017.v10i5.17137

\section{INTRODUCTION}

Historically, oral drug administration has been the predominant route for drug delivery. During the past two decades, numerous oral delivery systems have been developed to act as drug reservoirs from which the active substance can be released over a defined period at a predetermined and controlled rate. From a pharmacokinetic point of view, the ideal sustained and controlled release dosage form should be comparable with an intravenous infusion, which supplies continuously the amount of drug needed to maintain constant plasma levels once the steady state is reached [1].

Although some important applications, including oral administration of peptide and protein drugs, can be used to prepare colonic drug delivery systems, targeting drugs to the colon by the oral route. More often, the drug absorption is unsatisfactory and highly variable among and between individuals, despite excellent in vitro release patterns. The reasons for this are essentially physiological and usually affected by the GI transit of the form, especially its gastric residence time, which appears to be one of the major causes of the overall transit time variability [2].

Hydrochlorothiazide is a diuretic of the benzothiadiazine class, and it was a very good choice drug in the management of mild to moderate hypertension. It inhibits sodium reabsorption in distal tubules causing increased excretion of sodium and water as well as potassium and hydrogen ions. Hydrochlorothiazide (HCTZ) is a poor water soluble drug having plasma half-life of 6-8 hrs and oral bioavailability is $70 \%$. Its absorption window lies in the stomach therefore as long as it retains in the gastric environment an enhanced bioavailability can be seen. The present study was undertaken with the objective to develop an optimized fluid bed dryer containing HCTZ as a model drug to improve absorption and it oral bioavailability. In the current study, the effect of polymer (HPMC K4M, K15M, and Carbopol 974 P), polymer concentration and viscosity on drug release behavior and the buoyancy properties of prepared formulations were evaluated.

\section{METHODS}

HCTZ obtained as a gift sample from hetero laboratories Hyderabad. HPMC K15M, HPMC K100M, and carbopol 974 P were obtained from Signet Chemical Corporation, Mumbai, Avicel pH 102, Talc, Conc. Hydrochloric acid, Aerosil, sodium Bicarbonate, magnesium stearate obtained from S.D. Fine Chemicals, Mumbai.

Preparation of compression HCTZ floating tablets by direct [3-5] All the ingredients were accurately weighed as per formula and dispensed in clean polythene covers. HCTZ were sifted through sieve No. 60. HPMC K15M, K100M, carbopol 974 P, xanthan gum, magnesium stearate USP-NF (Avicel PH 102), microcrystalline cellulose Ph 102, Talc, and sodium bicarbonate passed through sieve No. 40. After sifting all the above ingredients were transferred into a big polythene cover and mixed for 10 minutes. Then tablets are compressed in compression machine at specified pressure with $9 \mathrm{~mm}$ "B" tooling round punch according to the formulae given in Table 1.

\section{Preparation of calibration curve for hydrochlorothiazide} Standard curve IN 0.1 N HCL

Accurately weighed $10 \mathrm{mg}$ of drug (hydrochlorothiazide) was first dissolved in $10 \mathrm{~mL}$ of methonal in $100 \mathrm{~mL}$ of volumetric flask to make a concentration of $1000 \mu \mathrm{g} / \mathrm{mL}$ (primary stock solution). $1 \mathrm{~mL}$ of primary stock solution was pipetted out into $10 \mathrm{~mL}$ of volumetric flask and volume was adjusted with water to make a concentration of $100 \mu \mathrm{g} / \mathrm{mL}$ (secondary stock solution). From the secondary stock solution, various concentrations such as $1,2,3,4,5 \ldots 10 \mu \mathrm{g} / \mathrm{mL}$ were prepared for the calibration curve. A standard curve was plotted by taking absorbance of secondary stock solutions in ultraviolet (UV) double beam spectrophotometer at $272 \mathrm{~nm}$.

Compatibility studies

Compatibility with excipients was confirmed by I R studies. The pure drug and its formulations along with excipients were subjected to IR 
Table 1: Composition of formulations

\begin{tabular}{|c|c|c|c|c|c|c|c|c|c|c|c|c|}
\hline Ingredients & F1 & F2 & F3 & F4 & F5 & F6 & F7 & F8 & F9 & F10 & F11 & F12 \\
\hline HCTZ & 25 & 25 & 25 & 25 & 25 & 25 & 25 & 25 & 25 & 25 & 25 & 25 \\
\hline HPMC K 15 & 90 & 120 & 150 & 45 & 60 & 75 & 45 & 60 & 75 & 45 & 60 & 75 \\
\hline Carbopol $974 \mathrm{p}$ & & & & 45 & 60 & 75 & & & & & & \\
\hline Xanthum gum & & & & & & & 45 & 60 & 75 & & & \\
\hline HPMC K-100 & & & & & & & & & & 45 & 60 & 75 \\
\hline $\mathrm{NaHCO}_{3}$ & 50 & 50 & 50 & 50 & 50 & 50 & 50 & 50 & 50 & 50 & 50 & 50 \\
\hline $\begin{array}{l}\text { Magnesium stearate USP-NF } \\
\text { (Avicel PH 102) }\end{array}$ & 3 & 3 & 3 & 3 & 3 & 3 & 3 & 3 & 3 & 3 & 3 & 3 \\
\hline Talc & 3 & 3 & 3 & 3 & 3 & 3 & 3 & 3 & 3 & 3 & 3 & 3 \\
\hline Microcrystalline cellulose Ph 102 & Q.S & Q.S & Q.S & Q.S & Q.S & Q.S & Q.S & Q.S & Q.S & Q.S & Q.S & Q.S \\
\hline Total & 300 & 300 & 300 & 300 & 300 & 300 & 300 & 300 & 300 & 300 & 300 & 300 \\
\hline
\end{tabular}

HCTZ: Hydrochlorothiazide

studies. In the present study, the potassium bromide disc (pellet) method was employed.

Evaluation of precompression blend $[3,6,7]$

The powder blend of all formulations was evaluated for bulk density, tapped density, compressibility index, Hausner ratio, and Angle of repose.

\section{A. Bulk density}

$30 \mathrm{~g}$ of material was passed through a sieve No. 25 to break up agglomerates and introduced into a dry $100 \mathrm{~mL}$ cylinder, without compacting, the powder was carefully leveled without compacting and the unsettled apparent volume, $\mathrm{V}_{0}$, was read. The bulk density was calculated, in $\mathrm{g} / \mathrm{mL}$, using the formula.

\section{$(\mathrm{M}) /\left(\mathrm{V}_{0}\right)$}

Where $\mathrm{M}=$ Total weight of the powder blend and $\mathrm{V}_{0}$ is the bulk volume of the powder blend.

\section{B. Tapped density}

After carrying out the procedure as given in the measurement of bulk density the cylinder containing the sample was tapped using a mechanically tapped density tester (Electrolab) that provides a fixed drop of $14 \pm 2 \mathrm{~mm}$ at a nominal rate of 300 drops/minute. The cylinder was tapped 500 times initially followed by an additional tap of 750 times until difference between succeeding measurement was $<2 \%$ and then tapped volume $\mathrm{V}_{\rho}$, was measured to the nearest graduated unit. The tapped density was calculated, in $\mathrm{g} / \mathrm{mL}$, using the formula:

\section{$(\mathrm{M}) /\left(\mathrm{V}_{\mathrm{f}}\right)$}

Where $\mathrm{M}=$ Total weight of the powder blend and $\mathrm{V}_{\mathrm{f}}$ is the tapped volume of the powder blend.

\section{Measures of powder compressibility}

The compressibility index and Hausner ratio are measures of the propensity of powder to be compressed. As such, they are measures of the relative importance of inter-particulate interactions. As such, they are measures of the relative importance of inter-particulate interactions. In a free-flowing powder, such interactions are generally less significant, and the bulk and tapped densities will be closer in value. For poorer flowing materials, there are frequently greater interparticle interactions and a greater difference between the bulk and tapped densities will be observed. These differences are reflected in the compressibility index and the Hausner ratio, which are calculated using the following formulae [8-11].

Compressibility index $=\left(\mathrm{V}_{\mathrm{r}}-\mathrm{V}_{0}\right) * 100 / \mathrm{V}_{\mathrm{r}}$

Where $\mathrm{V}_{\mathrm{r}}$ = tapped density; $\mathrm{V}_{0}=$ Bulk density.

\section{Hausner ratio}

It is the ratio of bulk density to tapped density.

$\mathrm{V}_{0} / \mathrm{V}_{\mathrm{f}}$

$\mathrm{V}_{0}=$ Bulk density; $\mathrm{V}_{\mathrm{r}}=$ Tapped density.

\section{E. Angle of repose}

The fixed funnel method was employed to measure the repose angle. A funnel was secured with its tip at a given height, $\mathrm{H}$ above a graph paper that was placed on a flat horizontal surface. The blend was carefully pored through the funnel until the apex of the conical pile just touched the tip of the funnel. The radius, $\mathrm{R}$, of the base of the conical pile was measured. The angle of repose, $\alpha$, was calculated using the following formula.

$\alpha=\tan ^{-1} \mathrm{H} / \mathrm{R}$

Determination of physical parameters of floating tablets $[3,6,7]$ Weight variation test

Totally, 20 tablets from each batch were individually weighed in grams on an analytical balance. The average weight and standard deviation were calculated, individual weight of each tablet was also calculated using the same and compared with average weight.

\section{Thickness test}

The thickness in millimeters ( $\mathrm{mm}$ ) was measured individually for 10 pre-weighed tablets by using Vernier Calipers. The average thickness and standard deviation were reported.

\section{Hardness test}

Tablet hardness was measured using a Monsanto hardness tester. The crushing strength of the 10 tablets with known weight and thickness of each was recorded in $\mathrm{kg} / \mathrm{cm}^{2}$ and the average hardness, and the standard deviation was reported.

\section{Friability test}

Totally, 20 tablets were selected from each batch and weighed. Each group of tablets was rotated at $25 \mathrm{rpm}$ for 4 minutes (100 rotations) in the Roche friabilator. The tablets were then dusted and re-weighed to determine the loss in weight. Friability was then calculated as per weight loss from the original tablets.

\section{Determination of drug content}

Ten tablets with pre-determined weight from each batch were taken and crushed in a mortar and weight equivalent to one average tablet was taken, transferred to a $250 \mathrm{~mL}$ volumetric flask and 0.1N HCL was added. The volume was then made up to the mark with 0.1N HCL. The solution was filtered, and the filtrate was sufficiently diluted, and the 
absorbance was recorded against the blank at $272 \mathrm{~nm}$. The drug content of the standard containing the drug powder was also determined. The drug content was determined by the formula [12-14].

$$
\text { Drug content }=\frac{\text { Amount in test }}{\text { Amount in standard }} \times 100
$$

The tablet passes the requirements if the amount of the active ingredient in each of the 10 tested tablets lies within the range of $85-115 \%$ of the stated amount.

\section{Ex-vivo bioadhesive strength [12-16]}

This evaluation test was conducted for all formulations. There is a gradual increase in bioadhesion strength was observed in from F4 to F6. This is due to the increase in the concentration of mucoadhesive polymer carbopol 974P. Here, the study investigates the mucoadhesive properties of formulations from $\mathrm{F} 4$ to $\mathrm{F} 6$. The maximum bioadhesion strength was found for formulations F4-FH 6, respectively. Bioadhesion is defined as the attachment of a synthetic or natural macromolecule to mucus and/or an epithelial surface. Bioadhesion strength is depends on molecular weight and swelling behavior of the polymers, contact time with mucus. As the concentration of carbopol increased the bioadhesive strength was also increased, the reason for such findings might be the formation of secondary bioadhesion bonds with mucin and interpenetration of the polymer chains in the interfacial region, while other polymers undergo superficial bioadhesion. Bioadhesion strength values of all the formulations represented in Table 2.

\section{In vitro buoyancy studies [16-20]}

The in vitro buoyancy $(\mathrm{n}=3)$ was determined by floating lag times according to the method described by Rosa et al. The tablets were placed in a beaker containing $100 \mathrm{~mL}$ of $0.1 \mathrm{~N}$ HCL. The time required for the tablet to rise to the surface and float was taken as floating lag time. Total floating time was also measured and shown in the results section in Table 3 and Fig. 1a-d.

\section{In vitro drug release studies [17-24]}

The release rate of hydrochlorothiazide floating tablets was determined using USP Type 2 apparatus. The dissolution test was performed in triplicate, using $900 \mathrm{~mL}$ of $0.1 \mathrm{~N} \mathrm{HCL}$, at $37 \pm 0.5^{\circ} \mathrm{C}$ at $50 \mathrm{rpm}$ for $12 \mathrm{hrs}$. A $5 \mathrm{~mL}$ sample was withdrawn from the dissolution apparatus at specified time points, and the samples were replaced with fresh dissolution medium. The samples were filtered through a $0.45 \mu \mathrm{m}$ membrane filter and diluted if necessary. The absorbance of these solutions was measured at $272 \mathrm{~nm}$ using Elico SL -159, UVvisible spectrophotometer. The cumulative drug release was calculated using the equation $(y=0.03 x+0.024)$ generated from Beer Lambert's Calibration curve in the linearity range of $1-10 \mu \mathrm{g} / \mathrm{mL}$

\section{Kinetic analysis of dissolution data [13-17]}

To analyze the in vitro release data various kinetic models were used to describe the release kinetics. The zero order rate equation 1 describes the systems where the drug release rate is independent of its concentration. The first order equation 2 describes the release from a system where release rate is concentration dependent. Higuchi described the release of drugs from insoluble matrix as a square root of time dependent process based on Fickian diffusion equation 3. The Hixson-Crowell cube root law equation 4 describes the release from systems where there is a change in surface area and diameter of particles or tablets [13-17].

$\mathrm{C}=\mathrm{K}_{0} \mathrm{t}$

Where $\mathrm{K}_{0}$ is zero-order rate constant expressed in units of concentration/time and $\mathrm{t}$ is the time.

$\log \mathrm{C}=\log \mathrm{C}_{0}, \mathrm{~K}_{1} \mathrm{t} / 2.303$
Table 2: Bioadhesive strength $(n=3)$ of all formulations

\begin{tabular}{lll}
\hline Formulation code & $\begin{array}{l}\text { Bio adhesion } \\
\text { strength }(\mathbf{g})\end{array}$ & $\begin{array}{l}\text { Force of } \\
\text { adhesion }(\mathbf{N}) \text { in dyne }\end{array}$ \\
\hline F1 & $9.4 \pm 0.28$ & 0.92 \\
F2 & $10.1 \pm 0.52$ & 0.99 \\
F3 & $15.6 \pm 0.39$ & 1.53 \\
F4 & $43.6 \pm 0.21$ & 4.27 \\
F5 & $44.2 \pm 0.36$ & 4.33 \\
F6 & $45.4 \pm 0.27$ & 4.45 \\
F7 & $22.5 \pm 0.15$ & 2.20 \\
F8 & $21.4 \pm 0.37$ & 2.09 \\
F9 & $24.2 \pm 0.46$ & 2.37 \\
F10 & $26.6 \pm 0.31$ & 2.60 \\
F11 & $28.2 \pm 0.42$ & 2.76 \\
F12 & $29.6 \pm 0.25$ & 2.90 \\
\hline
\end{tabular}

Table 3: In vitro buoyancy studies

\begin{tabular}{lll}
\hline Formulation code & $\begin{array}{l}\text { Floating lag } \\
\text { time (seconds) }\end{array}$ & Total floating time (hrs) \\
\hline F1 & 75 & $>12$ \\
F2 & 82 & $>12$ \\
F3 & 76 & $>12$ \\
F4 & 70 & $>12$ \\
F5 & 89 & $>12$ \\
F6 & 84 & $>12$ \\
F7 & 90 & $>12$ \\
F8 & 75 & $>12$ \\
F9 & 84 & $>12$ \\
F10 & 79 & $>12$ \\
F11 & 87 & $>12$ \\
F12 & 86 &
\end{tabular}

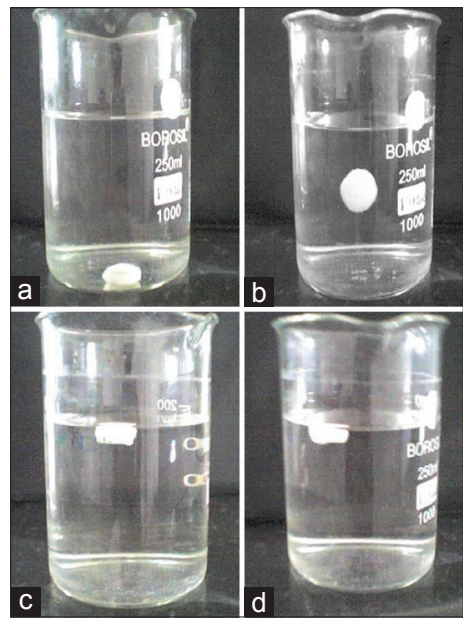

Fig. 1: In vitro buoyancy study of formulation F4. (a) At initial time, (b) after 34 seconds, (c) after 45 seconds, (d) after 12 hrs

Where $\mathrm{C}_{0}$ is the initial concentration of drug and $\mathrm{K}_{1}$ is the first order constant.

$\mathrm{Q}=\mathrm{K}_{\mathrm{H}} \mathrm{t}^{1 / 2}$

Where $\mathrm{K}_{\mathrm{H}}$ is the constant reflecting the design variables of the system.

$\mathrm{Q}_{0}{ }^{1 / 3}-\mathrm{Q}_{\mathrm{t}}{ }^{1 / 3}=\mathrm{K}_{\mathrm{HC}} \mathrm{t}$

Where $Q_{t}$ is the amount of drug remained in time $t, Q_{0}$ is the initial amount of the drug in tablet, and $\mathrm{K}_{\mathrm{HC}}$ is the rate constant for HixsonCrowell rate equation. Kinetic results were shown in the Table 4. 
Table 4: Kinetic values obtained from in vitro released data of formulation F4

\begin{tabular}{lll}
\hline Kinetic model & Slope & $\mathbf{R}^{\mathbf{2}}$ \\
\hline Zero-order plot & 8.3466 & 0.9366 \\
First-order plot & -0.0041 & 0.9364 \\
Higuchi plot & 29.935 & 0.9974 \\
Korsmeyer-Peppas & 0.7212 & 0.9680 \\
Hixon-crowel & 0.0298 & 0.9283 \\
\hline
\end{tabular}

Standard graph of doxofylline

The standard graph of doxofylline in $0.1 \mathrm{~N}$ HCL showed a good linearity with $\mathrm{R}^{2}$ of 0.999 , in the concentration range of $0-32 \mu \mathrm{g} / \mathrm{mL}$ at $272 \mathrm{~nm}$ shown in the Fig. 2 .

Properties of the powder blend

All formulations were evaluated for compressibility index, angle of repose, and Hausner ratio. The results indicated the pre-compressed blend gas good flow shown in Table 5.

Table 5: Evaluation of precompression parameters

\begin{tabular}{|c|c|c|c|c|c|c|}
\hline \multirow{2}{*}{$\begin{array}{l}\text { Formulation } \\
\text { code }\end{array}$} & \multicolumn{6}{|c|}{ Evaluation of precompression parameters } \\
\hline & Bulk density $(\mathrm{g} / \mathrm{mL})$ & Tapped density $(\mathrm{g} / \mathrm{mL})$ & Porosity (\%) & Carr's index (\%) & Hausner ratio & Angle of repose $\left({ }^{\theta}\right)$ \\
\hline F1 & 0.489 & 0.604 & 0.200 & 20.11 & 1.229 & 35.55 \\
\hline F3 & 0.479 & 0.610 & 0.199 & 19.99 & 1.221 & 33.33 \\
\hline F4 & 0.482 & 0.607 & 0.207 & 20.12 & 1.122 & 39.61 \\
\hline F5 & 0.488 & 0.603 & 0.190 & 19.07 & 1.23 & 37.13 \\
\hline F6 & 0.481 & 0.604 & 0.204 & 20.36 & 1.25 & 32.16 \\
\hline F7 & 0.488 & 0.606 & 0.222 & 19.99 & 1.299 & 33.66 \\
\hline F8 & 0.545 & 0.704 & 0.225 & 16.25 & 1.194 & 29.14 \\
\hline F9 & 0.504 & 0.601 & 0.199 & 22.64 & 1.29 & 30.15 \\
\hline F10 & 0.500 & 0.606 & 0.190 & 21.20 & 1.999 & 28.99 \\
\hline F11 & 0.501 & 0.605 & 0.195 & 20.65 & 1.385 & 35.54 \\
\hline F12 & 0.535 & 0.607 & 0.204 & 19.91 & 1.229 & 32.89 \\
\hline
\end{tabular}

Table 6: Evaluation of post-compression parameters

\begin{tabular}{|c|c|c|c|c|c|}
\hline \multirow[t]{2}{*}{ Formulation } & \multicolumn{5}{|c|}{ Evaluation of post-compression parameters } \\
\hline & Hardness of tablets* $\left(\mathrm{kg} / \mathrm{cm}^{2}\right)$ & Friability of tablets* (\%) & $\begin{array}{l}\text { Weight variation of } \\
\text { tablets* (mg) (\%) }\end{array}$ & $\begin{array}{l}\text { Thickness of } \\
\text { tablets* (mm) }\end{array}$ & Drug content (\%) \\
\hline F1 & $5.51 \pm 0.01$ & $0.23 \pm 0.05$ & $300 \pm 2$ & $5.12 \pm 0.02$ & 96.28 \\
\hline $\mathrm{F} 2$ & $4.54 \pm 0.06$ & $0.21 \pm 0.06$ & $300 \pm 2$ & $4.52 \pm 0.05$ & 97.23 \\
\hline F3 & $4.12 \pm 0.03$ & $0.20 \pm 0.05$ & $300 \pm 2$ & $4.23 \pm 0.01$ & 99.12 \\
\hline $\mathrm{F} 4$ & $4.35 \pm 0.09$ & $0.17 \pm 0.04$ & $300 \pm 2$ & $6.13 \pm 0.03$ & 98.85 \\
\hline F5 & $5.42 \pm 0.02$ & $0.19 \pm 0.03$ & $300 \pm 2$ & $4.0 \pm 0.06$ & 99.54 \\
\hline F6 & $4.58 \pm 0.08$ & $0.20 \pm 0.08$ & $300 \pm 2$ & $4.4 \pm 0.08$ & 99.43 \\
\hline F7 & $4.31 \pm 0.19$ & $0.23 \pm 0.05$ & $300 \pm 2$ & $4.2 \pm 0.01$ & 98.67 \\
\hline F8 & $4.47 \pm 0.11$ & $0.21 \pm 0.06$ & $300 \pm 2$ & $5.5 \pm 0.02$ & 98.97 \\
\hline F9 & $4.49 \pm 0.14$ & $0.20 \pm 0.05$ & $300 \pm 2$ & $5.3 \pm 0.04$ & 98.28 \\
\hline F10 & $5.4 \pm 0.12$ & $0.20 \pm 0.05$ & $300 \pm 2$ & $5.2 \pm 0.03$ & 99.43 \\
\hline F11 & $4.33 \pm 0.21$ & $0.22 \pm 0.07$ & $300 \pm 2$ & $4.35 \pm 0.06$ & 98.12 \\
\hline F12 & $4.30 \pm 0.04$ & $0.21 \pm 0.03$ & $300 \pm 2$ & $5.7 \pm 0.05$ & 99.48 \\
\hline
\end{tabular}

Table 7: In vitro drug release study of various formulations

\begin{tabular}{|c|c|c|c|c|c|c|c|c|c|c|c|c|}
\hline \multirow[t]{2}{*}{ Time } & \multicolumn{12}{|c|}{ Various formulation of \% drug release } \\
\hline & F1 & F2 & F3 & F4 & F5 & F6 & F7 & F8 & F9 & F10 & F11 & F12 \\
\hline 0 & 0 & 0 & 0 & 0 & 0 & 0 & 0 & 0 & 0 & 0 & 0 & 0 \\
\hline 0.5 & 13.2 & 10.6 & 9.6 & 15.8 & 12.8 & 11.7 & 13.6 & 11.2 & 9.7 & 12.8 & 11.3 & 9.9 \\
\hline 1 & 17.3 & 14.8 & 11.7 & 23.1 & 17.6 & 15.1 & 20.7 & 10.3 & 10.2 & 15.6 & 13.5 & 12.6 \\
\hline 2 & 20.6 & 16.4 & 12.9 & 31.3 & 21.9 & 18.6 & 28.3 & 14.7 & 12.9 & 19.2 & 17.8 & 14.8 \\
\hline 3 & 26.9 & 22.9 & 17.3 & 40.8 & 31.9 & 22.7 & 34.5 & 20.9 & 15.7 & 24.9 & 20.8 & 18.7 \\
\hline 5 & 42.1 & 39.1 & 32.6 & 55.1 & 46.9 & 34.4 & 51.6 & 32.8 & 29.1 & 40.7 & 36.3 & 31.8 \\
\hline 6 & 54.3 & 44.3 & 38.4 & 62.7 & 51.9 & 41.8 & 58.6 & 37.5 & 36.5 & 52.8 & 41.4 & 38.9 \\
\hline 7 & 67.5 & 51.6 & 43.7 & 70.4 & 57.6 & 54.4 & 64.4 & 44.6 & 41.6 & 65.2 & 48.8 & 47.6 \\
\hline 8 & 73.7 & 59.9 & 57.3 & 76.3 & 64.4 & 58.5 & 69.4 & 51.8 & 54.6 & 72.6 & 57.3 & 53.7 \\
\hline 9 & 79.2 & 67.7 & 62.9 & 81.9 & 70.6 & 63.4 & 76.2 & 59.8 & 60.4 & 78.3 & 64.7 & 60.8 \\
\hline 10 & 82.5 & 74.2 & 69.3 & 86.5 & 77.5 & 69.2 & 81.7 & 67.8 & 67.2 & 81.6 & 70.8 & 69.7 \\
\hline 11 & 87.8 & 78.5 & 73.1 & 90.9 & 81.6 & 74.3 & 87.2 & 76.5 & 70.6 & 86.5 & 76.3 & 72.3 \\
\hline 12 & 90.1 & 81.3 & 78.1 & 98.8 & 87.6 & 80.8 & 94.8 & 83.2 & 78.9 & 90.8 & 84.7 & 73.7 \\
\hline
\end{tabular}


Drug-excipient interaction studies

Fourier transform infrared spectroscopic studies (FTIR)

The FTIR spectra of drug and optimized formulation were recorded in Figs. 3 and 4. The characteristic peaks of the optimized formulation followed the same trajectory as that of the drug alone with minor differences. Thus, there may be no drug-excipient interactions.

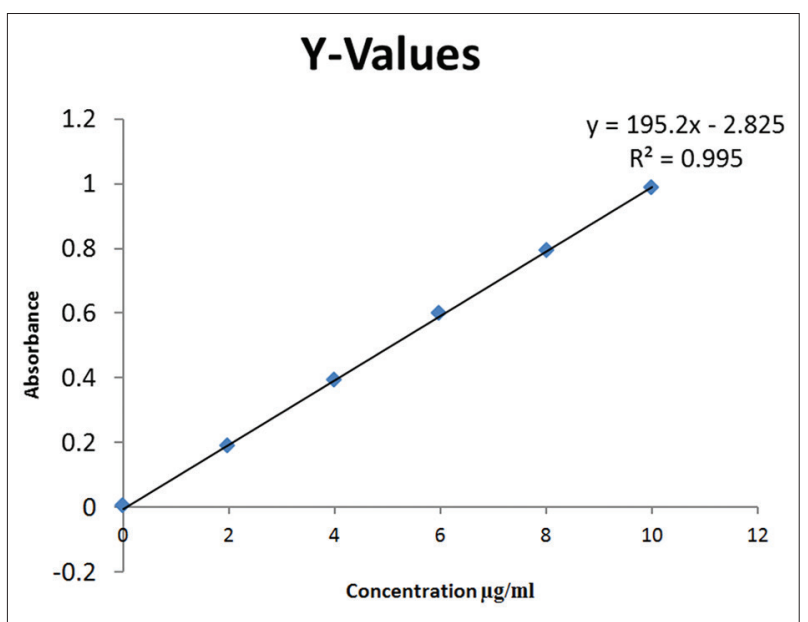

Fig. 2: Standard calibration curve of hydrochlorothiazide at $\lambda_{\text {max }}$ $272 \mathrm{~nm}$
Evaluation of the prepared tablets for physical parameters

All formulations were tested for physical parameter such as hardness, thickness, weight variation, friability, and drug content. All estimated parameters were found to be within the limits shown in Table 6.

\section{In vitro dissolution studies}

Based on the dissolution release studies keeping in view of bioadhesion strength formulation F4-F6 were considered to be in good floating as well as bioahesion property based on similarity factor with innovator drug dissolution profile formulae F4 were considered as optimized formulae dissolution release pattern observed in Table 7 and dissolution profiles seen in Fig. 5.

Table 8: Comparison of drug profile of optimized batch with innovator

\begin{tabular}{lll}
\hline Batch No. & Similarity factor (F2) & Difference factor (F1) \\
\hline F1 & 73.8 & 26.6 \\
F2 & 73.9 & 26.1 \\
F3 & 73.9 & 26.1 \\
F4 & 73.71 & 25.3 \\
F5 & 73.73 & 25.5 \\
F6 & 78.64 & 24.5 \\
F7 & 79.66 & 24.6 \\
F8 & 84.29 & 16.81 \\
F9 & 76.22 & 24.7 \\
F10 & 75.6 & 25.1 \\
\hline
\end{tabular}

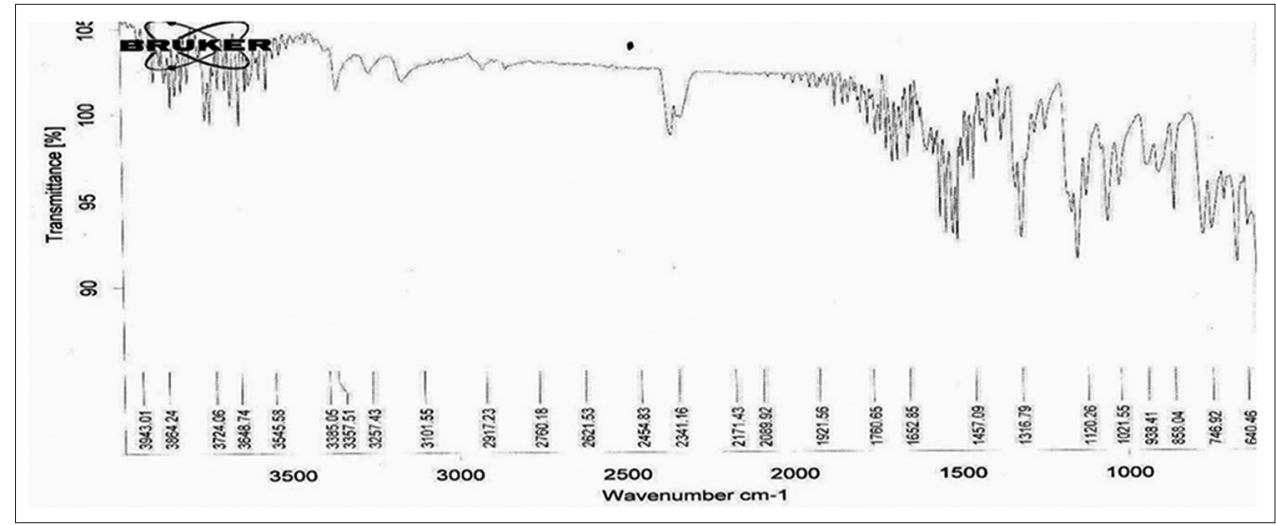

Fig. 3: Fourier transform infrared spectrum of hydrochlorothiazide pure drug

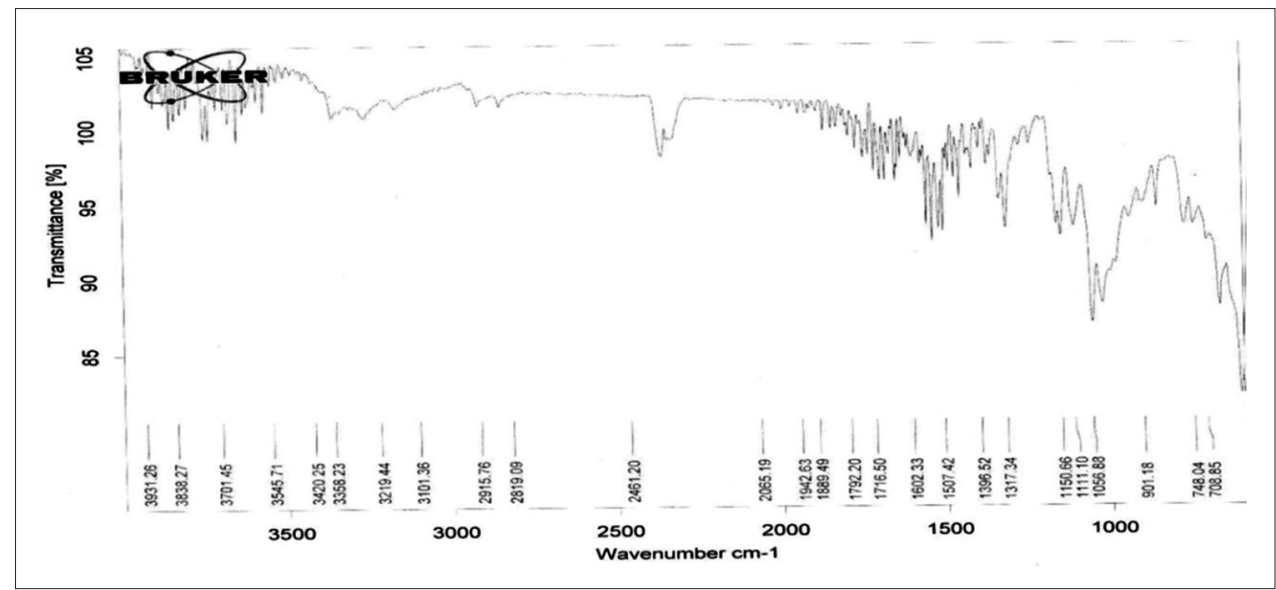

Fig. 4: Fourier transform infrared of hydrochlorothiazide best formulation F4 


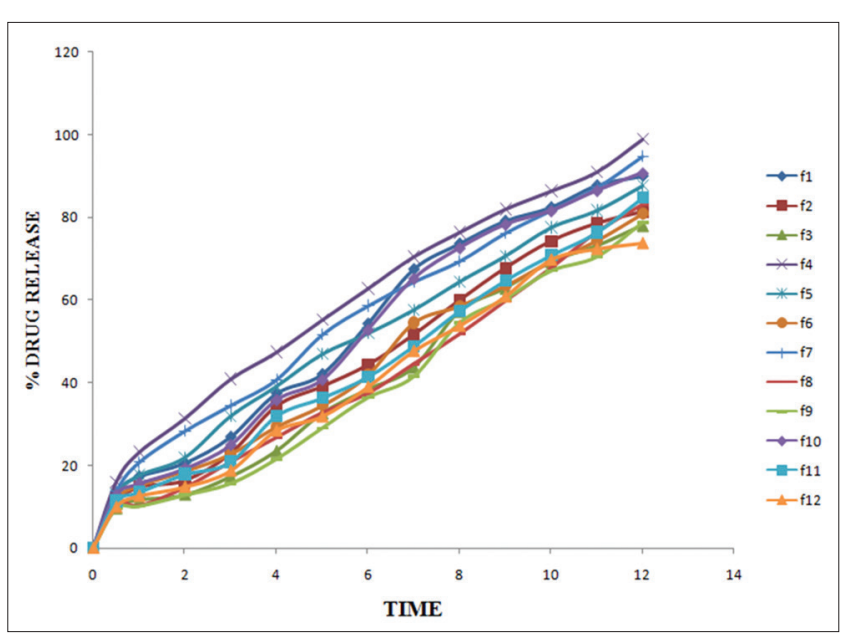

Fig. 5: Dissolution profile graphs

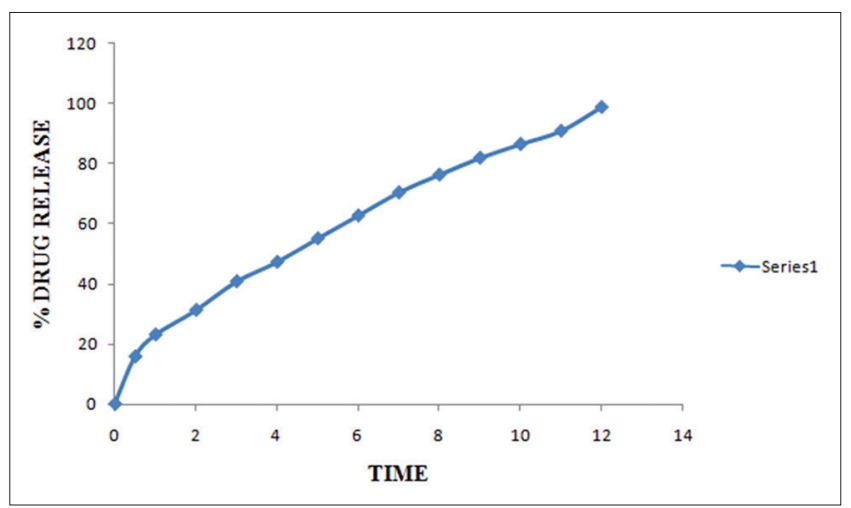

Fig. 6: Best \% drug release F4

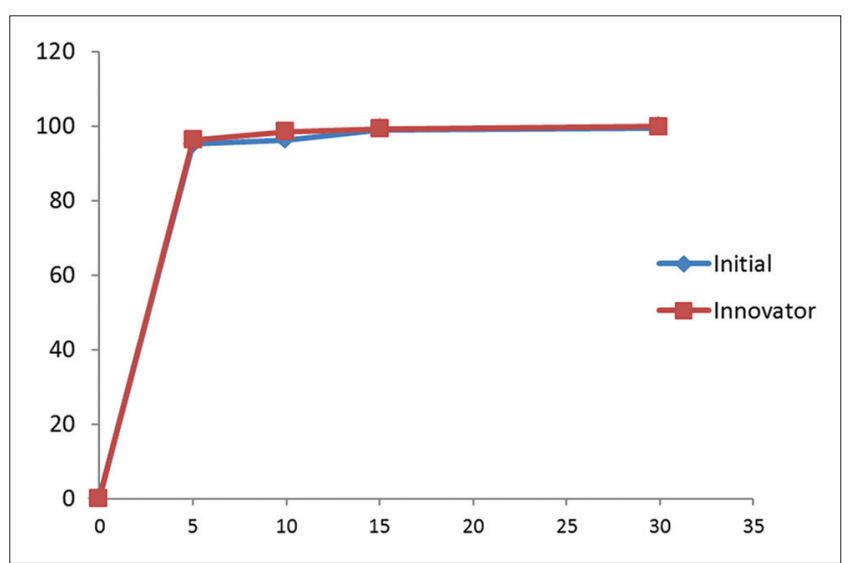

Fig. 7: Graphical representation of dissolution profile of innovator versus optimized batch (F4) initially

\section{Data treatment}

From Table 8, similarity factor for $\mathrm{F} 4$ formulation was found to be more, i.e., 84.29 compared to other formulations and difference factor was found to be less, i.e., 16.81 compared to other formulations. Therefore, F4 formulation said to be comparable with that of innovator product where the similar matching dissolution profiles can be seen in Figs. 6 and 7.

\section{CONCLUSION}

From the compatibility studies, it was concluded that HPMC K15, K100, xanthan gum, carbopol 974 p, sodium bicarbonate, magnesium stearate, talc, and microcrystalline cellulose were compatible with hydrochlorothizide and thus suitable for the formulation of hydrochlorothizide floating tablets. In vitro buoyancy studies were performed for all the formulations, F1-F12 by using $0.1 \mathrm{~N}$ HCL solution at $37^{\circ} \mathrm{C}$. All the formulations were floated. The formulation F4-F6 containing of HPMC K 4M and carbopol 974 P showed more Bioadhesive strength than other formulations. In vitro dissolution studies were also performed for all formulations. The formulation F4 showed the controlled release for $12 \mathrm{hrs}$. Thus, F4 was identified as ideal batch based on its results.

\section{REFERENCES}

1. Grant S. Nizatidine. An updated review of its pharmacodynamic and pharmacokinetic properties and therapeutic use in peptic ulcer and other allied diseases. Drugs 1989;37:801-70.

2. Bandameedi R, Pandiyan S. Formulation and evaluation of floating osmotic tablets of nizatidine. J Appl Pharm 2015;7:209.

3. Whitehead L, Fell JT, Collett JH. Development of a gastroretentive dosage form. Eur J Pharm Sci 1996;4(1):182.

4. Hwang SJ, Park H, Park K. Gastric retentive drug-delivery systems. Crit Rev Ther Drug Carrier Syst 1998;15(3):243-84.

5. Ramu B, Manasa MS. Formulation and evaluation of colon specific drug delivery of press coated lansoprazole tablets. Indo Am J Pharm Res 2015:5(4):1523-32.

6. Padmavathy J, Saravanan D, Rajesh D. Formulation and evaluation of ofloxacin floating tablets using HPMC. Int J Pharm Pharm Sci 2011;3(1):170-3.

7. $\mathrm{Li} \mathrm{YH}, \mathrm{Zhu}$ JB. Modulation of combined release behaviours from a novel tablets-in-capsules system. J Control Release 2004;50:111-22.

8. Korsmeyer RW, Gurny R, Doelker E, Buri P, Peppas NA. Mechanism of solute release from porous hydrophilic polymers. Int J Pharm 1983;15:25-35.

9. Lachman L, Libermann HA, Kaning JL. Tablets. The Theory and Practice of Industrial Pharmacy. $3^{\text {rd }}$ ed. Mumbai: Varghese Publication; 1987. p. 318-20.

10. Hadjiioannou TP, Christian GD, Koupparis MA. Quantitative Calculations in Pharmaceutical Practices and Research. New Delhi: NY-VCH Publishers Inc.; 1993. p. 345-8.

11. Bourne DW. Pharmacokinetics. In: Banker GS, Rhodes CT, editors. Modern Pharmaceutical. $4^{\text {th }}$ ed. New York, NY: Marcel Dekker Inc.; 2002. p. 67-92.

12. Dey S, Dutta S, Mazumder B. Formulation and evaluation of floating matrix tablet of atenolol for gastro-retentive drug delivery. Int J Pharm Pharm Sci 2013;4:433-7.

13. Siepmann J, Peppas NA. Modeling of drug release from delivery system based on hydroxypropyl methylcellulose (HPMC). Adv Drug Deliv Rev 2001;48:139-57.

14. Lee JW, Park JH, Robinson JR. Bioadhesive based dosage forms: The next generation. J Pharm Sci 2000;89:850-66

15. Higuchi T. Mechanism of sustained action medication. Theoretical analysis of rate of release of solid drugs dispersed in solid matrices. J Pharm Sci 1963;52:1145-9.

16. Alexander S, Juergen S, Roland B. Drug delivery to the upper small intestine window using gastroretentive technologies. Curr Opin Pharmacol 2006;6:501-8.

17. Whitehead L, Fell JT, Sharma HL. Floating dosage forms: An in vivo study demonstrating prolonged gastric retention. J Control Release $1998: 55: 3-12$

18. Hardman JG, Limbird LE, Gilman AG. The Pharmacological Basis of Therapeutics. New York: McGraw Hill; 2001. p. 774.

19. James WA. Expandable Gastric Retention Device. 2004. US Patent US2004/0219186A1.

20. Shato H, Miyagawa Y, Okabe T. Dissolution mechanism of diclofenac sodium from wax matrix granules. J Pharm Sci 1997;86:929-34.

21. Sulthana A, Ramu B, Srikanth G, Rajkamal B. Formulation and evaluation of colon specific tinidazole matrix tablets. 2016;8(3):1-6. DOI: 10.5958/0975-4377.2016.00022.7.

22. Hossain MS, Banik S, Islam MS. Formulation design and characterization of kollidon SR based trimetazidine dihydrochloride matrix tablets. India J Pharm Educ Res 2012;46:136-44

23. Rosa M, Zia $\mathrm{H}$, Rhodes T. Design and testing in vitro of a bioadhesive and floating drug delivery system for oral application. Int J Pharm 1994;105:65-70.

24. Colombo P, Bettini R, Santi P, Ascentiis DA, Peppas NA. Analysis of the swelling and release mechanisms from drug delivery systems with emphasis on drug solubility and water transport. J Control Release 1996;39:231-7. 